CLINICAL STUDY

\title{
Serum adiponectin is associated with family history of diabetes independently of obesity and insulin resistance in healthy Korean men and women
}

\author{
Jae Woong Sull ${ }^{1,2}$, Hee Jin Kim ${ }^{1,2}$, Ji Eun Yun ${ }^{1,2}$, Grace Kim ${ }^{3}$, Eun Jung Park ${ }^{1,4}$, Soriul Kim ${ }^{1,4}$, Hee Yeon Lee ${ }^{1,4}$ \\ and Sun Ha Jee ${ }^{1,2}$ \\ ${ }^{1}$ Graduate School of Public Health, Institute for Health Promotion and ${ }^{2}$ Department of Epidemiology and Health Promotion, Graduate School of Public \\ Health, Yonsei University, Seoul 120-752, Republic of Korea, ${ }^{3}$ School of Medicine, Johns Hopkins University, Baltimore, Maryland, USA and ${ }^{4}$ Metabolic \\ Syndrome Research Initiatives, Seoul, Republic of Korea \\ (Correspondence should be addressed to S H Jee; Email: jsunha@yumc.yonsei.ac.kr)
}

\begin{abstract}
Background: Adiponectin has been reported as a new risk factor for the development of diabetes. However, it is not clear whether adiponectin levels are associated with family history of diabetes (FHD). Objective: The objective of this study was to measure the independent association of serum adiponectin with FHD in relation to insulin resistance and obesity.

Methods: In 2006, a cross-sectional study was conducted in which waist circumference (WC), body mass index (BMI), and serum adiponectin were measured in 5919 healthy Korean men and women. Multiple linear regression models were used to assess the association of serum adiponectin levels with FHD. The population was classified into two groups according to median values for each of the following variables: WC, BMI, and homeostasis model assessment of insulin resistance (HOMA-IR). Results: The positive FHD group had higher HOMA-IR and lower adiponectin levels in both men and women than those without FHD. Adiponectin levels were significantly associated with FHD in men and women respectively, after adjusting for age, BMI, and alcohol consumption $(P=0.0123$ and 0.0004). The relationship between adiponectin and FHD was similar between the high and low insulin resistance, BMI, and WC groups in male non-smokers and in all Korean women.

Conclusion: These results confirm that adiponectin levels are associated with FHD. These data also suggest that the association of serum adiponectin with FHD may be independent of obesity and insulin resistance.
\end{abstract}

European Journal of Endocrinology $16039-43$

\section{Introduction}

Adiponectin has been reported as a new risk factor for the development of diabetes. Exclusively secreted by adipose tissue, ADIPOQ is a 244-amino acid protein that regulates the metabolism of lipids and glucose, and circulates quite abundantly in plasma (1-5). ADIPOQ decreases insulin resistance and body weight by increasing lipid oxidation in muscle and other organs such as the pancreas and liver (6). Plasma ADIPOQ concentrations are also reduced in individuals with obesity, diabetes mellitus, or coronary heart disease $(7,8)$.

Family history of diabetes (FHD) has been associated with hypoadiponectinemia in some (9-13) but not all studies (14-16). However, previous studies generally had small sample sizes that may explain the inconsistencies in findings. The underlying mechanisms of association between FHD and ADIPOQ levels are not yet fully understood. Because ADIPOQ levels can be used to predict increased insulin sensitivity (14), the inverse association between ADIPOQ and FHD may be due to insulin resistance $(14,17)$. However, the literature on the association of serum ADIPOQ levels with FHD independently of insulin resistance is sparse. Thus, the purpose of this study was to see whether the association between FHD and ADIPOQ levels in relation to insulin resistance and obesity is independent.

\section{Materials and methods}

\section{Study subjects}

The study population comprised 6551 subjects who participated in the Korean Metabolic Syndrome Research Initiative and had routine health examinations at the Health Promotion Center in University Hospitals from January to December 2006. The objective and contents of this research project were explained to participants who volunteered to undergo the health examinations. Recruitment of these 
volunteered subjects took place only after informed consent had been obtained. Participating hospitals are listed in the appendix (18). The analysis excluded subjects with missing information on waist circumference (WC), body mass index (BMI), or ADIPOQ levels, and those who had a history of cancer, cardiovascular disease, stroke, or diabetes $(n=292)$. We also excluded those who had been on medication for diabetes and subjects with a fasting blood sugar $>110 \mathrm{mg} / \mathrm{dl}$ $(n=340)$. Finally, 5919 subjects, aged between 24 and 87 years were selected for subsequent analysis. The Institutional Review Board of Human Research of Yonsei University approved the study, and written informed consent was obtained from all subjects.

\section{Data collection}

Each participant was interviewed using a structured questionnaire to collect the history of cigarette smoking (never smoked, ex-smoker, or current smoker) and alcohol consumption (non-drinker or drinker of any amount of alcohol), as well as other demographic characteristics such as age, gender, and FHD. FHD was defined as subjects with at least one first-degree relative with diabetes (parent or sibling). Both current and ex-smokers were asked to report the average number of cigarettes they smoke or had smoked per day. WC was measured midway between the lower rib and the iliac crest. Weight and height were measured while the participants were wearing light clothing. BMI was calculated as weight $(\mathrm{kg})$ divided by the square of height $\left(\mathrm{m}^{2}\right)$. Blood pressure was measured for the patient in a seated position by a registered nurse or blood pressure technician using a standard mercury sphygmomanometer or automatic manometer. Both systolic and diastolic blood pressures were measured after a 15-min rest.

\section{Measurement of biomarkers}

For the clinical chemistry assay, serum was separated from peripheral venous blood samples that were obtained from each participant after $12 \mathrm{~h}$ of fasting, and was stored at $-70{ }^{\circ} \mathrm{C}$ for $2 \mathrm{~h}$. Metabolic syndrome biomarkers such as fasting blood glucose, total cholesterol (TC), triglycerides (TG), and high density lipoprotein cholesterol (HDL-C) were measured using the Hitachi-7600 analyzer (Hitachi Ltd). For subjects with serum available, ADIPOQ levels were measured using an ELISA (Mesdia Co., Ltd, Seoul, Republic of Korea) (18). Insulin resistance was calculated using the homeostasis model assessment of insulin resistance (HOMA-IR). HOMA indices were calculated as follows: HOMA $=$ fasting insulin $(\mu \mathrm{lU} / \mathrm{ml}) \times$ fasting glucose $(\mathrm{mmol} / \mathrm{l}) / 22.5$. The intra- and interassay variances for the ADIPOQ were $6.3-7.4 \%$ and $4.5-8.6 \%$ respectively. Data quality control was performed in accordance with the procedures of the Korean Association of Laboratory Quality Control.

\section{Statistical analysis}

All biomarkers except ADIPOQ were found to have a normal distribution. Therefore, ADIPOQ levels are presented as median interquartile range and were logtransformed in the multivariate analyses. The independent $t$-test was used to analyze the statistical differences among the characteristics of the study participants. The mean serum ADIPOQ level was calculated for each category of FHD. Multiple linear regression models were used to assess the associations of serum ADIPOQ levels with FHD. Current smokers were further divided into two groups of 1-10 and 10 and more cigarettes per day. Analyses were adjusted for age at enrollment (continuous variable), BMI, and smoking status.

To examine the association between FHD and ADIPOQ stratified by insulin resistance (HOMA-IR), BMI, and WC, we divided our study samples into two groups (by median values) of HOMA-IR $(<0.795$ and $\geq 0.795)$, BMI $(<24.48$ and $\geq 24.48)$, and WC $(<85$ and $\geq 8)$ for men and HOMA-IR $(<0.705$ and $\geq 0.705)$, BMI $(<22.3$ and $\geq 22.3)$, and WC $(<74.5$ and $\geq 74.5$ ) for women. All analyses were conducted using SAS statistical software, version 9.0 (SAS Institute Inc, Cary, NC, USA). All statistical tests were two-sided, and statistical significance was determined as $P<0.05$.

\section{Results}

The characteristics of participants in relation to their FHD are shown for Korean men in Table 1. Male subjects with FHD were on average younger than those without FHD. In general, those with FHD had higher WC, BMI, FBS, TC, HOMA, and insulin levels, and had lower ADIPOQ levels. However, HDL cholesterol, C-reactive protein (CRP), and smoking status were similar for the two groups. For women, subjects with FHD were also on average younger than those without FHD (Table 2). Those with FHD generally had higher FBS and HOMA levels, and women with FHD had lower ADIPOQ levels. However, WC, BMI, HDL cholesterol, and CRP measurements were similar for the two groups (Table 2).

Using the age-adjusted Pearson correlation test, levels of ADIPOQ were found to be inversely associated with BMI, WC, and TG, and directly associated with HDL cholesterol $(P<0.001)$. However, the correlation between CRP and ADIPOQ was not significant $(P=0.3228$; data not shown). ADIPOQ levels were significantly associated with FHD in men and women respectively, after adjusting for age, BMI, and alcohol drinking $(P=0.0123$ and 0.0004; Table 3). When HOMA index was added as a covariate, the association didn't change much in men and women $(P=0.0177$ and 0.0004 ; data not shown).

To control for potential confounding by insulin resistance and obesity, data were further stratified by BMI, WC, and HOMA (Table 4). For men, the relationship between ADIPOQ and FHD was statistically significant in 
Table 1 General characteristics of healthy Korean men according to family history of diabetes.

\begin{tabular}{|c|c|c|c|}
\hline \multirow[b]{2}{*}{$N$} & \multicolumn{2}{|c|}{ Family history of diabetes } & \multirow[b]{2}{*}{$P$ value } \\
\hline & $\begin{array}{l}\text { Negative } \\
(N=2825) \\
\text { Mean } \pm \text { s.D. }\end{array}$ & $\begin{array}{l}\text { Positive } \\
(N=503) \\
\text { Mean } \pm \text { S.D. }\end{array}$ & \\
\hline Age (year) & $45.7 \pm 9.3$ & $43.4 \pm 7.3$ & $<0.0001$ \\
\hline WC $(\mathrm{cm})$ & $84.9 \pm 7.2$ & $86.0 \pm 7.4$ & 0.0022 \\
\hline BMI $\left(\mathrm{kg} / \mathrm{m}^{2}\right)$ & $24.5 \pm 2.6$ & $24.9 \pm 2.8$ & 0.0038 \\
\hline $\mathrm{ADIPOQ}^{\mathrm{a}}(\mu \mathrm{g} / \mathrm{ml})$ & $6.20 \pm 4.7$ & $5.65 \pm 4.1$ & 0.0005 \\
\hline $\log _{\text {ADIPOQ }}{ }^{\mathrm{a}}$ & $2.52 \pm 0.8$ & $2.42 \pm 0.7$ & 0.0006 \\
\hline FBS $(\mathrm{mg} / \mathrm{dl})$ & $90.5 \pm 8.3$ & $92.6 \pm 8.5$ & $<0.0001$ \\
\hline SBP $(\mathrm{mmHg})$ & $123.0 \pm 13.6$ & $123.5 \pm 11.9$ & 0.4353 \\
\hline $\mathrm{DBP}(\mathrm{mmHg})$ & $77.9 \pm 10.8$ & $77.6 \pm 10.4$ & 0.6599 \\
\hline Total cholesterol (mg/dl) & $186.8 \pm 30.2$ & $191.0 \pm 30.9$ & 0.0046 \\
\hline HDL cholesterol (mg/dl) & $49.9 \pm 11.0$ & $49.6 \pm 10.9$ & 0.5934 \\
\hline LDL cholesterol (mg/dl) & $115.5 \pm 28.2$ & $117.5 \pm 28.2$ & 0.2117 \\
\hline Triglyceride (mg/dl) & $142.1 \pm 92.3$ & $149.6 \pm 101.9$ & 0.1004 \\
\hline C-reactive protein (mg/dl) & $0.16 \pm 0.3$ & $0.16 \pm 0.3$ & 0.9726 \\
\hline HOMA & $0.93 \pm 0.7$ & $1.02 \pm 0.7$ & 0.0067 \\
\hline \multirow{2}{*}{\multicolumn{4}{|c|}{ Smoking status (\%) }} \\
\hline & & & \\
\hline Ex & 34.8 & 33.2 & 0.3663 \\
\hline Current & 40.0 & 38.6 & \\
\hline Alcohol drinking (\%) & 88.5 & 89.5 & 0.5433 \\
\hline
\end{tabular}

$P$ values refer to differences between groups as determined by $t$-test and $\chi^{2}$ test for continuous and categorical variables respectively. FBS, fasting plasma glucose; BMI, body mass index; WC, waist circumference; SBP systolic blood pressure; DBP, diastolic blood pressure; HOMA, homeostasis model assessment; HDL, high density lipoprotein; LDL, low density lipoprotein.

a Median \pm interquartile range (IQR)

subjects with $\mathrm{BMI}<24.48$, in those with $\mathrm{WC} \geq 85$ and in non-smokers, while this relationship was not significant in the other groups (Table 4). However, when the analyses were performed only on non-smokers and light smokers, ADIPOQ levels were significantly associated with FHD in both BMI groups. The WC and HOMA groups also showed similar associations of ADIPOQ levels with FHD.

For women, ADIPOQ levels in the FHD group were significantly lower among those with HOMA $<0.705(P$ value $=0.0377)$ and with $\mathrm{HOMA} \geq 0.705(P$ value $=$ 0.0036) respectively, compared with the non-FHD group (Table 4). Similar associations of ADIPOQ levels with FHD were seen in the BMI and WC groups.

\section{Discussion}

Our study demonstrates that FHD is associated with hypoadiponectinemia that supports findings of previous studies $(9,10)$. In a recent study, in 64-year-old women in Sweden, mean ADIPOQ levels were lower (11.4 vs 13.9) in those with FHD than those without FHD (10). In another study in male subjects in Sweden, firstdegree relatives of type 2 diabetic patients also had significantly lower ADIPOQ levels (9). The present study showed an inverse relationship between FHD and ADIPOQ levels in Korean men and women. For men, the association was stronger in non-smokers which
Table 2 General characteristics of healthy Korean women according to family history of diabetes.

\begin{tabular}{|c|c|c|c|}
\hline \multirow[b]{2}{*}{$N$} & \multicolumn{2}{|c|}{ Family history of diabetes } & \multirow[b]{2}{*}{$P$ value } \\
\hline & $\begin{array}{l}\text { Negative } \\
(N=2141) \\
\text { Mean } \pm \text { s.D. }\end{array}$ & $\begin{array}{l}\text { Positive } \\
(N=450) \\
\text { Mean } \pm \text { s.D. }\end{array}$ & \\
\hline Age (year) & $44.4 \pm 9.5$ & $43.2 \pm 7.9$ & 0.0033 \\
\hline Waist (cm) & $74.9 \pm 7.8$ & $75.3 \pm 7.9$ & 0.3777 \\
\hline $\mathrm{BMI}\left(\mathrm{kg} / \mathrm{m}^{2}\right)$ & $22.7+2.9$ & $22.8+2.8$ & 0.5237 \\
\hline $\mathrm{ADIPOQ}^{\mathrm{a}}(\mu \mathrm{g} / \mathrm{ml})$ & $10.0 \pm 7.4$ & $8.7 \pm 6.7$ & 0.0001 \\
\hline $\log _{\text {ADIPOQ }}{ }^{\mathrm{a}}$ & $3.0 \pm 0.7$ & $2.9 \pm 0.7$ & $<0.0001$ \\
\hline FBS $(\mathrm{mg} / \mathrm{dl})$ & $86.6 \pm 7.9$ & $89.2 \pm 8.3$ & $<0.0001$ \\
\hline $\mathrm{SBP}(\mathrm{mmHg})$ & $115.2 \pm 13.8$ & $116.1 \pm 14.6$ & 0.2343 \\
\hline $\mathrm{DBP}(\mathrm{mmHg})$ & $71.7 \pm 10.2$ & $71.6 \pm 10.5$ & 0.9820 \\
\hline Total cholesterol (mg/dl) & $182.3 \pm 32.9$ & $181.6 \pm 30.3$ & 0.6440 \\
\hline HDL cholesterol (mg/dl) & $59.5 \pm 13.0$ & $58.8 \pm 12.2$ & 0.2755 \\
\hline LDL cholesterol (mg/dl) & $108.5 \pm 30.4$ & $105.7 \pm 27.5$ & 0.0597 \\
\hline Triglyceride (mg/dl) & $90.6 \pm 52.7$ & $89.3 \pm 51.1$ & 0.6369 \\
\hline C-reactive protein $(\mathrm{mg} / \mathrm{dl})$ & $0.12 \pm 0.2$ & $0.11 \pm 0.2$ & 0.6152 \\
\hline HOMA & $0.81 \pm 0.6$ & $0.88 \pm 0.6$ & 0.0386 \\
\hline Insulin $(\mu \mathrm{IU} / \mathrm{ml})$ & $3.75 \pm 2.6$ & $3.93 \pm 2.5$ & 0.1795 \\
\hline \multicolumn{4}{|l|}{ Smoking status (\%) } \\
\hline Ex & 2.5 & 1.8 & 0.1034 \\
\hline Current & 4.1 & 2.2 & \\
\hline Alcohol drinking (\%) & 51.2 & 52.8 & 0.5124 \\
\hline
\end{tabular}

$P$ values refer to differences between groups as determined by $t$-test and $\chi^{2}$ test for continuous and categorical variables respectively. FBS, fasting plasma glucose; BMI, body mass index; WC, waist circumference; SBP, systolic blood pressure; DBP, diastolic blood pressure; HOMA, homeostasis model assessment; HDL, high density lipoprotein; LDL, low density lipoprotein.

${ }^{a}$ Median \pm interquartile range (IQR).

implies that smoking is a confounding factor. Moreover, in male non-smokers and in Korean women, the relationship remained even when performing subgroup analyses of the HOMA-IR, BMI, and WC categories, suggesting that the association of serum ADIPOQ with FHD is independent of obesity and insulin resistance.

The present study was performed with a larger sample size than that of other studies, and like these previous

Table 3 Multiple linear regression model of mean log ADIPOQ in healthy Korean men and women.

\begin{tabular}{|c|c|c|c|c|}
\hline \multirow[b]{2}{*}{ Variables } & \multicolumn{2}{|c|}{ Model 1} & \multicolumn{2}{|c|}{ Model 2} \\
\hline & $\beta$ & $P$ value & $\beta$ & $P$ value \\
\hline \multicolumn{5}{|l|}{ Men } \\
\hline Age (year) & 0.007 & $<0.0001$ & 0.005 & $<0.0001$ \\
\hline $\begin{array}{l}\text { Family history of } \\
\text { diabetes }\end{array}$ & -0.077 & 0.0042 & -0.066 & 0.0123 \\
\hline BMI $\left(\mathrm{kg} / \mathrm{m}^{2}\right)$ & & & -0.040 & $<0.0001$ \\
\hline \multicolumn{5}{|l|}{ Smoking status } \\
\hline Ex & & & -0.007 & 0.7881 \\
\hline Current & & & -0.076 & 0.0017 \\
\hline \multicolumn{5}{|l|}{ Women } \\
\hline Age (year) & 0.005 & 0.0001 & 0.009 & $<0.0001$ \\
\hline $\begin{array}{l}\text { Family history of } \\
\text { diabetes }\end{array}$ & -0.113 & 0.0001 & -0.103 & 0.0004 \\
\hline BMI $\left(\mathrm{kg} / \mathrm{m}^{2}\right)$ & & & -0.037 & $<0.0001$ \\
\hline \multicolumn{5}{|l|}{ Smoking status } \\
\hline Ex & & & 0.104 & 0.1511 \\
\hline Current & & & 0.037 & 0.5274 \\
\hline
\end{tabular}


Table 4 Multiple linear regression model ${ }^{\mathrm{a}}$ of mean log ADIPOQ for family history of diabetes (yes) by BMI, WC, and HOMA in healthy Korean men and women.

\begin{tabular}{|c|c|c|c|c|c|c|c|c|c|c|}
\hline \multirow[b]{2}{*}{ Variables } & \multirow[b]{2}{*}{ Subgroups } & \multicolumn{3}{|c|}{$\begin{array}{c}\text { All men FHD } \\
\text { (yes) }\end{array}$} & \multicolumn{3}{|c|}{$\begin{array}{c}\text { Non or light smoking men FHD } \\
\text { (yes) }\end{array}$} & \multicolumn{3}{|c|}{$\begin{array}{c}\text { All women FHD } \\
\text { (yes) }\end{array}$} \\
\hline & & $N$ & $\beta$ & $P$ value & $N$ & $\beta$ & $P$ value & $N$ & $\beta$ & $P$ value \\
\hline \multirow[t]{2}{*}{$\mathrm{BMI}\left(\mathrm{kg} / \mathrm{m}^{2}\right)$} & $<24.48$ & 1666 & -0.083 & 0.0359 & 549 & -0.140 & 0.0225 & 1292 & -0.122 & 0.0036 \\
\hline & $\geq 24.48$ & 1662 & -0.054 & 0.1308 & 488 & -0.134 & 0.0384 & 1299 & -0.084 & 0.0375 \\
\hline \multirow[t]{2}{*}{ WC (cm) } & $<85$ & 1574 & -0.046 & 0.2502 & 525 & -0.114 & 0.0436 & 1334 & -0.066 & 0.1070 \\
\hline & $\geq 85$ & 1754 & -0.072 & 0.0427 & 512 & -0.140 & 0.0308 & 1257 & -0.143 & 0.0006 \\
\hline \multirow[t]{2}{*}{ HOMA } & $<0.795$ & 1664 & -0.057 & 0.1450 & 534 & -0.156 & 0.0170 & 1297 & -0.090 & 0.0377 \\
\hline & $\geq 0.795$ & 1664 & -0.065 & 0.0704 & 503 & -0.101 & 0.0934 & 1294 & -0.115 & 0.0036 \\
\hline
\end{tabular}

Adjusted for age, BMI, and alcohol drinking. BMI, body mass index; WC, waist circumference; HOMA, homeostasis model assessment; FHD, family history of diabetes; light smokers, subjects who smoke $<10$ cigarettes per day.

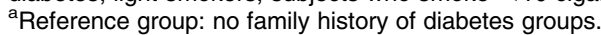

studies, we also found that lower serum ADIPOQ concentrations in FHD groups were not dependent on insulin resistance status or obesity. Because ADIPOQ predicts increased insulin sensitivity (14), the inverse association between ADIPOQ and obesity, T2DM, or FHD may to a large extent, be explained by the parallel occurrence of insulin resistance $(14,17)$. However, a recent cross-sectional study in Sweden reported that a FHD was associated with low serum ADIPOQ concentrations independently of obesity, glycemia, or insulin sensitivity, although the study was limited by the fact that all of the study subjects were 64-year-old women (10). Two other studies have reported that ADIPOQ levels are reduced in lean offspring of type 2 diabetes subjects maintaining that the inverse association of $A D I P O Q$ levels with FHD is independent of BMI $(9,12)$.

We observed a sex difference in the association of ADIPOQ with FHD in this Korean population. Women showed a stronger association of ADIPOQ with FHD than did men. One of the possible reasons of the difference is a clear difference in TG concentration between men and women in the present study. Serum triglyceride levels were much higher in men than in women. However, mean TG levels were significantly lower in male non-smokers than in male current smokers (119.2 and $151.3 \mathrm{mg} / \mathrm{dl}$; data not shown). When the analyses were performed according to smoking status in men, the association of ADIPOQ with FHD appeared stronger in non-smokers. This observation along with recent studies which have reported that smoking status is associated with lower levels of ADIPOQ (19-21), suggests that smoking is a possible confounder in the association between ADIPOQ and FHD. The possible causes of sex differences in the association of ADIPOQ levels with FHD should be investigated further.

This study has several limitations. Due to its crosssectional design, this study cannot elucidate mechanisms or determine the direction of causality of the relationship between ADIPOQ and FHD. A single assessment of ADIPOQ levels may be susceptible to short-term variation, which would bias the results toward the null. However, Pischon et al. reported that intra-individual ADIPOQ levels are reasonably stable over time, with an intra-class correlation coefficient of
0.85 for ADIPOQ levels measured within the same participants 1 year apart (22). Another limitation of this study is the classification of FHD. We did not classify the types of diabetes. However, type 2 diabetes is the most common type of diabetes in the Republic of Korea, while the incidence rate of type 1 diabetes in the country is among the lowest reported in the world. During the period 1995-2000, the age-adjusted incidence of type 1 diabetes was 1.36 per 100 000/year $(23,24)$.

In summary, these results confirm that ADIPOQ concentrations are lower in first-degree relatives of diabetic patients, and suggest that the association may not be due to the concomitant presence of insulin resistance and obesity. Further studies should be performed in other populations to confirm the association between ADIPOQ and FHD regardless of insulin resistance.

\section{Declaration of interest}

The authors declare that there is no conflict of interest that could be perceived as prejudicing the impartiality of the research reported.

\section{Funding}

This study was funded by the Seoul City R\&BD program (10526).

\section{Acknowledgements}

This study was funded by the Seoul City R\&BD program (10526).

\section{References}

1 Stefan N, Vozarova B, Funahashi T, Matsuzawa Y, Weyer C, Lindsay RS, Youngren JF, Havel PJ, Pratley RE, Boqardus C \& Tataranni PA. Plasma adiponectin concentration is associated with skeletal muscle insulin receptor tyrosine phosphorylation, and low plasma concentration precedes a decrease in whole-body insulin sensitivity in humans. Diabetes 200251 1884-1888.

2 Bacci S, Menzaghi C, Ercolino T, Ma X, Rauseo A, Salvemini L, Vigna C, Fanelli R, Di Mario U, Doria A \& Trischitta V. The +276 
G/T single nucleotide polymorphism of the adiponectin gene is associated with coronary artery disease in type 2 diabetic patients. Diabetes Care 200427 2015-2020.

3 Kita A, Yamasaki H, Kuwahara H, Moriuchi A, Fukushima K, Kobayashi M, Fukushima T, Takahashi R, Abiru N, Uotani S, Kawasaki E \& Eguchi K. Identification of the promoter region required for human adiponectin gene transcription: association with CCAAT/enhancer binding protein-beta and tumor necrosis factor-alpha. Biochemical and Biophysical Research Communications $2005331484-490$.

4 Fasshauer M, Klein J, Neumann S, Eszlinger M \& Paschke R. Hormonal regulation of adiponectin gene expression in 3T3-L1 adipocytes. Biochemical and Biophysical Research Communications 2002290 1084-1089.

5 Filippi E, Sentinelli F, Trischitta V, Romeo S, Arca M, Leonetti F, Di Mario U \& Baroni MG. Association of the human adiponectin gene and insulin resistance. European Journal of Human Genetics 2004 12 199-205.

6 Yamauchi T, Kamon J, Waki H, Terauchi Y, Kubota N, Hara K, Mori Y, Ide T, Murakami K, Tsuboyama-Kasaoka N, Ezaki O, Akanuma Y, Gavrilova O, Vinson C, Reitman ML, Kagechika H, Shudo K, Yoda M, Nakano Y, Tobe K, Nagai R, Kimura S, Tomita M, Froguel P \& Kadowaki T. The fat-derived hormone adiponectin reverses insulin resistance associated with both lipoatrophy and obesity. Nature Medicine 20017 941-946.

7 Hotta K, Funahashi T, Arita Y, Takahashi M, Matsuda M, Okamoto Y, Iwahashi H, Kuriyama H, Ouchi N, Maeda K, Nishida M, Kihara S, Sakai N, Nakajima T, Haseqawa K, Muraquchi M, Ohmoto Y, Nakamura T, Yamashita S, Hanafusa T \& Matsuzawa Y. Plasma concentrations of a novel, adipose-specific protein, adiponectin, in type 2 diabetic patients. Arteriosclerosis, Thrombosis, and Vascular Biology $2000201595-1599$.

8 Diez JJ \& Iglesias P. The role of the novel adipocyte-derived hormone adiponectin in human disease. European Journal of Endocrinology 2003148 293-300.

9 Pellmé F, Smith U, Funahashi T, Matsuzawa Y, Brekke H, Wiklund O, Taskinen MR \& Jansson PA. Circulating adiponectin levels are reduced in nonobese but insulin-resistant first-degree relatives of type 2 diabetic patients. Diabetes 200352 1182-1186.

10 Behre CJ, Brohall G, Hulthe J \& Fagerberg B. Serum adiponectin in a population sample of 64-year-old women in relation to glucose tolerance, family history of diabetes, autoimmunity, insulin sensitivity, C-peptide, and inflammation. Metabolism 200655 188-194.

11 Civitarese AE, Jenkinson CP, Richardson D, Bajaj M, Cusi K, Kashyap S, Berria R, Belfort R, DeFronzo RA, Mandarino LJ \& Ravussin E. Adiponectin receptors gene expression and insulin sensitivity in non-diabetic Mexican Americans with or without a family history of Type 2 diabetes. Diabetologia 200447 816-820.

12 Kowalska I, Straczkowski M, Nikolajuk A, Krukowska A, Kinalska I \& Górska M. Plasma adiponectin concentration and tumor necrosis factor alpha system activity in lean non-diabetic offspring of type 2 diabetic subjects. European Journal of Endocrinology 2006154 319-324.

13 Tesauro M, Rizza S, Iantorno M, Campia U, Cardillo C, Lauro D, Leo R, Turriziani M, Cocciolillo GC, Fusco A, Panza JA, Scuteri A, Federici M, Lauro R \& Quon MJ. Vascular, metabolic, and inflammatory abnormalities in normoglycemic offspring of patients with type 2 diabetes mellitus. Metabolism 200756 413-419.
14 Tschritter O, Fritsche A, Thamer C, Haap M, Shirkavand F, Rahe S, Staiger H, Maerker E, Häring H \& Stumvoll M. Plasma adiponectin concentrations predict insulin sensitivity of both glucose and lipid metabolism. Diabetes 200352 239-243.

15 Kriketos AD, Greenfield JR, Peake PW, Furler SM, Denyer GS, Charlesworth JA \& Campbell LV. Inflammation, insulin resistance, and adiposity: a study of first-degree relatives of type 2 diabetic subjects. Diabetes Care 200427 2033-2040.

16 Retnakaran R, Connelly PW, Sermer M, Zinman B \& Hanley AJ. The impact of family history of diabetes on risk factors for gestational diabetes. Clinical Endocrinology 200767 754-760.

17 Weyer C, Funahashi T, Tanaka S, Hotta K, Matsuzawa Y, Pratley RE \& Tataranni PA. Hypoadiponectinemia in obesity and type 2 diabetes: close association with insulin resistance and hyperinsulinemia. Journal of Clinical Endocrinology and Metabolism 200186 1930-1935.

18 Yoon SJ, Lee HS, Lee SW, Yun JE, Kim SY, Cho E, Lee SJ, Lee EJ, Lee HY, Park J, Kim HS \& Jee SH. The association between adiponectin and diabetes in the Korean population. Metabolism $200857853-857$.

19 Takefuji S, Yatsuya H, Tamakoshi K, Otsuka R, Wada K, Matsushita K, Sugiura K, Hotta Y, Mitsuhashi H, Oiso Y \& Toyoshima H. Smoking status and adiponectin in healthy Japanese men and women. Preventive Medicine $2007 \mathbf{4 5} 471-475$.

20 Abbasi F, Farin HM, Lamendola C, McLaughlin T, Schwartz EA, Reaven GM \& Reaven PD. The relationship between plasma adiponectin concentration and insulin resistance is altered in smokers. Journal of Clinical Endocrinology and Metabolism $2006 \mathbf{9 1}$ 5002-5007.

21 Iwashima Y, Katsuya T, Ishikawa K, Kida I, Ohishi M, Horio T, Ouchi N, Ohashi K, Kihara S, Funahashi T, Rakugi H \& Ogihara T. Association of hypoadiponectinemia with smoking habit in men. Hypertension $2005 \mathbf{4 5} 1094-1100$.

22 Pischon T, Hotamisligli GS \& Rimm EB. Adiponectin: stability in plasma over 36 hours and within-person variation over 1 year. Clinical Chemistry $2003 \mathbf{4 9}$ 650-652.

23 DIAMOND Project Group. Incidence and trends of childhood Type 1 diabetes worldwide 1990-1999. Diabetic Medicine 200623 857-866.

24 Rhee BD. Epidemiological characteristics of diabetes mellitus among Korean population. Journal of Korean Diabetes Association 200327 173-178.

\section{Appendix}

List of participating hospitals in Korean Metabolic Syndrome Research Initiatives: Severance Hospital, Yonsei University; Ewha Women's University; Seoul National University; Korea University.

Received 29 September 2008

Accepted 22 October 2008 